\title{
Intimate partner violence: Assessment in the era of telehealth
}

\author{
Laura Marie LaPlante, MD
}

ntimate partner violence (IPV) includes "physical violence, sexual violence, stalking, and psychological aggression (including coercive tactics) by a current or former intimate partner." ${ }^{\prime 1}$ Intimate partner violence was a widespread problem even before COVID-19, with lifetime rates of nearly 35\% among White women, 28\% among White men, and highest amongst those who identify as people of color, lesbian, or bisexual. ${ }^{1}$ The COVID-19 pandemic has magnified risk factors for IPV such as unemployment and social isolation-particularly in marginalized communities-while decreasing access to resources such as childcare and shelters. ${ }^{2}$ Because most individuals do not voluntarily disclose or seek treatment for IPV, it is critical we use the following recommendations to complete safe, trauma-informed, recoveryoriented assessment in patients presenting for care, whether in person or via telehealth.

\section{Ensure a safe environment}

At the onset of a telehealth appointment, ask the patient "Who is in the room with you?" If an adult or child age $>2$ years is present, do not assess for IPV because it may be unsafe for the patient to answer such questions. Encourage the patient to use privacy-enhancing strategies (eg, wearing headphones, going outside, calling from a vehicle). Be flexible; someone may not be able to discuss IPV during an appointment but might be able to at a different time, such as when their partner goes to work. For patients who disclose IPV, identify a word, phrase, or gesture to quickly communicate their partner's presence or need for immediate help. ${ }^{2}$ While the "Signal for Help" (ie, thumb first tucked into the palm, then covered with fingers to form a fist) has been developed, ${ }^{3}$ it is not universally familiar; until then, establish specific communications and preferences with each patient. Include a plan for the patient to abruptly disconnect (eg, "You have the wrong number") with a pre-determined method of follow-up.

\section{Obtain informed consent}

Before asking a patient about IPV, provide psychoeducation about the purpose, including its relationship to one's health. Acknowledge reasons it may not be safe to provide and/or document answers, and describe limits of confidentiality and local mandated reporting requirements.

\section{Standardize the assessment}

Intimate partner violence assessment should be normalized (eg, "Because violence is common, I ask everyone about their relationships"), direct, and well-integrated. Know whether your site uses a specific IPV screening tool, such as the Relationship Health and Safety Screen (RHSS), which is used at the VA; if so, learn and practice asking the specific questions aloud until it feels routine and you can maintain eye

\section{Every issue of CURRENT PsychiatRY} has its 'Pearls'

\section{Yours could be found here.}

Read the 'Pearls' guidelines for manuscript submission at MDedge.com/ CurrentPsychiatry/page/pearls. Then, share with your peers a 'Pearl' of wisdom from your practice.
Dr. LaPlante is Assistant Professor, Department of Psychiatry and Behavioral Sciences, University of Washington, Seattle, Washington.

Disclosure

The author reports no financial relationships with any companies whose products are mentioned in this article, or with manufacturers of competing products.

doi: $10.12788 / \mathrm{cp} .0172$

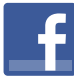

Discuss this article at www.facebook.com/ MDedgePsychiatry 
Provide options

instead of

instructions,

which will

empower patients

to choose what is

best for them contact throughout. Examples of other IPV assessment instruments include the Abuse Assessment Screen (AAS); Hurt, Insult, Threaten, and Scream (HITS), Partner Violence Screen (PVS), and Women Abuse Screening Tool (WAST). ${ }^{4}$ Pay attention to the populations in which a tool has been studied, any associated copyright fees, and gender-neutral and non-heteronormative language. Avoid asking leading questions (eg, "You're not being hurt, are you?") or using charged/interpretable terms (eg, "Is someone abusing you?").

\section{Document with intention}

Use person-centered, recovery-oriented language (eg, someone who experiences or uses IPV) rather than stigmatizing language (eg, victim, batterer, abuser). Describe what happened using the individual's own words and clearly identify the source of information, witnesses, and any weapons used. Choose nonpejorative language (ie, "states" instead of "claims"). Do not document details of the safety plan in the chart because doing so can compromise safety.

\section{Provide resources and referrals}

Regardless of whether a patient consents to screening/documentation or discloses IPV, you should offer universal education, resources, and referrals. Review national contacts (National Domestic Violence Hotline: 1-800-799-7233), community agencies (available through www.domestic shelters.org), and suggested safety apps such as myPlan (www.myplanapp.org), but do not send a patient electronic or physical materials without first confirming it is safe to do so. Assess the patient's interest in legal steps (eg, obtaining a protection order, pressing charges) while recognizing and respecting valid concerns about law enforcement involvement, particularly among the Black community and Black transgender women. Provide options instead of instructions, which will empower patients to choose what is best for their situation, and support their decisions.

\section{References}

1. Breiding MJ, Chen J, Black MC. Intimate partner violence in the United States - 2010. National Center for Injury Prevention and Control, Centers for Disease Control and Prevention. Published February 2014. Accessed January 12, 2021. https://www.cdc.gov/violenceprevention/pdf/ cdc_nisvs_ipv_report_2013_v17_single_a.pdf

2. Evans ML, Lindauer JD, Farrell ME. A pandemic within a pandemic - intimate partner violence during Covid-19. N Engl J Med. 2020;383(24):2302-2304. doi:10.1056/ NEJMp2024046

3. Canadian Women's Foundation. Signal for help. 2020. Accessed January 12, 2021. https://canadianwomen.org/ signal-for-help/

4. Basile KC, Hertz MF, Back SE. Intimate partner violence and sexual violence victimization assessment instruments for use in healthcare settings: Version 1. Centers for Disease Control and Prevention, National Center for Injury Prevention and Control. 2007. Accessed January 12, 2021. https://www.cdc.gov/violenceprevention/pdf/ipv/ ipvandsvscreening.pdf 